\title{
Evidence for X-Linkage of Tibial Length and Body Length
}

\author{
STANLEY M. GARN, KEITH P. HERTZOG \\ AND CHRISTABEL G. ROHMANN ${ }^{1}$ \\ Center for Human Growth and Development, University of Michigan, Ann \\ Arbor, Michigan and Department of Anthropology, University \\ of Pennsylvania, Philadelphia, Pennsylvania
}

\begin{abstract}
Sister-sister, brother-brother and sister-brother similarities in both tibial. length and stature from one month through 10 years are in accord with the hypothesis of partial X-linkage, they reject the hypothesis of selective inactivation of an $X$ chromosome, and they indicate that the complex that is body length is suited to simplistic analysis.
\end{abstract}

In a series of previous studies, we have provided growing evidence for least partial involvement of the $X$ chromosome in a wide variety of developmental and dimensional events. The parameters include tooth size, both mesiodistal and buccolingual, tooth formation (i.e. calcification, root elongation and movement) and postnatal ossification timing, as shown by both parent-child and sibling intergenerational and intragenerational correlations (Garn and Rohmann, '62a, '62b, '66; Garn, Rohmann and Davis, '63; Garn, Kerewsky and Lewis, '66; Garn, Lewis and Kerewsky, '65a, '65b, '67; Garn and McCreery, '69; Garn, Rohmann and Hertzog, '69). These results have been confirmed in part by Lewis and Grainger ('67) and Goose ('67) for crown size in Canadian and British children, and they have been discussed, in part, by Acheson ('66) and Hunt ('66), among others.

In the present study we have extended the data design to include a single-bone measurement, that is the length of the tibial metaphysis, testing the assumption that genetic and chromosomal effects are more likely to be elucidated in single bones than in complexes involving bones of different types. Therefore, like-sexed and cross-sexed sibling comparisons are also included for the more conventional measurement of body length both as a comparison and to extend our studies on the possible involvement of the $\mathrm{X}$ chromosome in multiple size factors.

\section{MATERIALS AND METHODS}

This study is based upon serial, longitudinal radiogrammetric and anthropometric measurements of like-sexed and unlikesexed sibling pairs from one month of age (0.08 years) through 10.0 years. Comparisons are therefore entirely within family lines and at identical ages, throughout. Tibial length measurements were made as the maximum calcified length of the metaphysis, to the nearest $0.1 \mathrm{~mm}$, on a Gerber Analog Data Reduction System (GADRS) with simultaneous card-punching and typewriter output. Bone length was measured as derived from the ouput and then computer-corrected for increasing radiographic enlargement due to enlargement of the lower leg in the course of growth. Body length, in turn, was measured as recumbent length through the seventh year and as standing height thereafter (cf. Garn and Shamir, '58).

Sister-sister, brother-brother and brothersister correlations were then made by computer, using the IBM 1620 electronic calculator. Raw scores rather than normalized T-scores were employed throughout the correlational procedure since the distibutions of both stature and tibial length were shown to be satisfactorily free from skewness and both approximated classical Gaussian distributions.

It should be observed that the serial, longitudinal approach employing like-sexed and cross-sexed siblings effectively elim-

\footnotetext{
1 Present address 51 Cottage St., Chagrin Falls, Ohio 44022 .
} 
inates the ubiquitous problem of sampling possibly divergent gene pools. At the same time, it introduces an indeterminant sampling bias which is then repeated in each age-interval considered. Hence the agefor-age data are not independent events, and in the statistical analysis that follows, this potentiality is clearly recognized.

\section{Findings}

As shown in the first table, sibling correlations for the length of the tibial metaphysis are systematically positive throughout and follow a consistent pattern. At all ages, from 0.08 years on, 23 sister-sister correlations exceed the comparable sisterbrother correlations and in 21 out of 23 comparisons exceed brother-brother correlations as well. While these differences in tibial similaity are statistically significant by the stochastic Chi-squared test at any reasonable level of confidence, the data are best summarized as the mean value of $r$ from the mean $z$ transform of $r$. Here, the best estimate of the true magnitude of sister-sister correlations is 0.71 , the comparable pooled value of $r$ for brotherbrother correlations is 0.48 and that for sister-brother correlations is 0.42 . Accordingly, sisters show systematically greater similarity in postnatal tibial development than either like-sexed brother-sister or cross-sexed brother-sister pairs.

Exactly the same correlational trend obtains for body length, i.e. recumbent length through 7 years and standing height thereafter. Without exception, sister-sister correlations exceed all 23 sister-brother correlations and, with but three exceptions, body length in sisters is more alike than body length in brothers. Here, mean values of $r$ are 0.66 for sister-sister correlations, 0.52 for brother-brother correlations, and 0.47 for cross-sexed brother-sister sibling correlations. Overall, the mean values of $r$, obtained from the mean $z$ transform of $r$, show exactly the same trends both for the single-bone roentgenogrammetric measurement and for the conventional anthropometric measurement. The comparable

TABLE 1

Extent of prepuberal sibling similarities and sex linkage in tibial length and body length

\begin{tabular}{|c|c|c|c|c|c|c|c|c|c|c|c|c|}
\hline \multirow{3}{*}{$\begin{array}{c}\text { Age } \\
\text { (years) }\end{array}$} & \multicolumn{6}{|c|}{ Tibial length } & \multicolumn{6}{|c|}{ Body length } \\
\hline & \multicolumn{2}{|r|}{$\begin{array}{l}\text { Sister- } \\
\text { sister } \\
\end{array}$} & \multicolumn{2}{|c|}{$\begin{array}{l}\text { Brother- } \\
\text { brother }\end{array}$} & \multicolumn{2}{|c|}{$\begin{array}{l}\text { Sister- } \\
\text { brother }\end{array}$} & \multicolumn{2}{|c|}{$\begin{array}{l}\text { Sister- } \\
\text { sister }\end{array}$} & \multicolumn{2}{|c|}{$\begin{array}{l}\text { Brother- } \\
\text { brother }\end{array}$} & \multicolumn{2}{|c|}{$\begin{array}{c}\text { Sister- } \\
\text { brother }\end{array}$} \\
\hline & $N$ & $\underline{r}$ & $N$ & $\underline{r}$ & $N$ & $\underline{r}$ & $N$ & $\underline{x}$ & $N$ & $\underline{r}$ & $N$ & $\underline{r}$ \\
\hline 0.08 & 19 & 0.399 & 49 & 0.435 & 76 & 0.135 & 62 & $0 . \overline{4} 63$ & 73 & 0.447 & 141 & 0.274 \\
\hline 0.25 & 19 & 0.404 & 42 & 0.202 & 64 & 0.229 & 65 & 0.562 & 72 & 0.464 & 152 & 0.376 \\
\hline 0.50 & 28 & 0.563 & 60 & 0.493 & 94 & 0.437 & 75 & 0.519 & 73 & 0.436 & 156 & 0.351 \\
\hline 0.75 & 25 & 0.553 & 40 & 0.553 & 67 & 0.253 & 68 & 0.477 & 68 & 0.519 & 145 & 0.357 \\
\hline 1.0 & 31 & 0.616 & 53 & 0.522 & 92 & 0.347 & 74 & 0.538 & 74 & 0.494 & 154 & 0.393 \\
\hline 1.5 & 21 & 0.490 & 38 & 0.459 & 55 & 0.282 & 72 & 0.489 & 67 & 0.512 & 146 & 0.369 \\
\hline 2.0 & 28 & 0.661 & 43 & 0.537 & 80 & 0.375 & 66 & 0.622 & 70 & 0.504 & 147 & 0.391 \\
\hline 2.5 & 23 & 0.606 & 27 & 0.500 & 50 & 0.438 & 68 & 0.582 & 66 & 0.493 & 136 & 0.472 \\
\hline 3.0 & 28 & 0.671 & 54 & 0.559 & 80 & 0.477 & 63 & 0.622 & 70 & 0.680 & 137 & 0.467 \\
\hline 3.5 & 19 & 0.695 & 32 & 0.562 & 52 & 0.407 & 58 & 0.653 & 66 & 0.583 & 126 & 0.532 \\
\hline 4.0 & 31 & 0.694 & 51 & 0.553 & 79 & 0.481 & 61 & 0.673 & 63 & 0.613 & 123 & 0.503 \\
\hline 4.5 & 16 & 0.585 & 29 & 0.526 & 44 & 0.406 & 55 & 0.719 & 70 & 0.598 & 117 & 0.569 \\
\hline 5.0 & 30 & 0.594 & 53 & 0.535 & 78 & 0.431 & 53 & 0.730 & 68 & 0.573 & 116 & 0.539 \\
\hline 5.5 & 15 & 0.748 & 28 & 0.501 & 38 & 0.587 & 50 & 0.737 & 70 & 0.517 & 111 & 0.565 \\
\hline 6.0 & 34 & 0.766 & 60 & 0.388 & 82 & 0.534 & 51 & 0.765 & 70 & 0.571 & 123 & 0.556 \\
\hline 6.5 & 30 & 0.783 & 43 & 0.405 & 65 & 0.500 & 49 & 0.744 & 66 & 0.534 & 113 & 0.524 \\
\hline 7.0 & 34 & 0.826 & 50 & 0.516 & 76 & 0.469 & 52 & 0.697 & 67 & 0.508 & 114 & 0.463 \\
\hline 7.5 & 31 & 0.828 & 43 & 0.458 & 66 & 0.471 & 51 & 0.755 & 63 & 0.535 & 109 & 0.503 \\
\hline 8.0 & 30 & 0.783 & 54 & 0.488 & 70 & 0.321 & 47 & 0.739 & 62 & 0.501 & 102 & 0.526 \\
\hline 8.5 & 29 & 0.879 & 32 & 0.510 & 55 & 0.453 & 41 & 0.724 & 64 & 0.517 & 100 & 0.514 \\
\hline 9.0 & 28 & 0.896 & 42 & 0.399 & 57 & 0.518 & 43 & 0.723 & 62 & 0.495 & 102 & 0.494 \\
\hline 9.5 & 20 & 0.868 & 26 & 0.328 & 43 & 0.483 & 42 & 0.710 & 60 & 0.458 & 93 & 0.449 \\
\hline 10.0 & 24 & 0.807 & 48 & 0.433 & 56 & 0.506 & 40 & 0.714 & 60 & 0.452 & 90 & 0.466 \\
\hline Mean $\mathrm{r}^{1}$ & & 0.711 & & 0.476 & & 0.420 & & 0.660 & & 0.522 & & 0.467 \\
\hline
\end{tabular}

\footnotetext{
1 From the mean $\underline{z}$ transform of $\underline{x}$.
} 
mean values of $r$ are within \pm 0.05 , throughout, and not systematically different in direction.

Accordingly, the totality of 138 age-specific, measurement-specific and pairingspecific length correlations, covering the period of 0.08 through 10 years, clearly indicates greater similarity of sisters as compared to brothers or brother-sister pairings, a finding that is consistent with the hypothesis of at least partial mediation of the $\mathrm{X}$ chromosome.

\section{DISCUSSION}

The findings in this particular study are particularly interesting in that they resolve an ancient debate. They show that, contrary to expectation, sister-sister, brotherbrother and sister-brother similarities in tibial length and body length ae rather similar. The tibial correlations and the stature correlations differ from each other by less than 0.05 on the average, and in no consistent direction. Thus, while the tibia is a single tubular bone and body length is a complex of 5 kinds of bones plus two fat pads (cf. Garn, '66) the two types of length measurements yield essentially similar results. Such a conclusion was also evident in our perinatal radiogrammetric comparisons of a decade ago (Garn, Greaney and Young, '56) and both give new confidence to intrapopulation comparisons using body length alone.

The findings also indicate that, from the first month on, sister-sister similarities exceed brother-brother similarities and these in turn exceed sister-brother similarities both for tibial length and for body length. Overall, these data are consistent with the hypothesis of partial X-mediation, a finding consistent with many other findings on both crown-size dimensions, tooth calcification, tooth movement, postnatal ossification timing, length of individual metacarpals and phalanges, metacarpal cortical thickness, and other developmental parameters. The 138 sex and age-specific correlations in the present study, add to nearly 1000 other correlations involving both sibling pairs and parent-child pairs, together tend to confirm the hypothesis of (partial) X-chromosomal mediation of developmental events. Either we have an incredible "run" in the exact gambler's sense, or numerous parameters of size and development all attest to a major role of the $\mathrm{X}$ chromosome as shown by both sibling comparisons and parent-child similarities.

The fact that sister-sister similarities exceed brother-brother similarities in both tibial length and body length from one month through 10 years of age is similarly incompatible with the hypothesis of selective inactivation of the paternal $\mathrm{X}$ chromosome; if it were, sisters would not be dimensionally more similar than brothers. Selective inactivation of the maternal $X$ in turn can not be rejected outright from these data (through it would tend to attenuate fraternal similarities), but such a likelihood is contraindicated by the greater relative variability of postnatal ossification timing in girls (cf. Garn and McCreery, '69).

Now the mechanism of X-linkage holds at least one micro-evolutionary potential in that intergenerational differences between males are then completely subject to random gene fluctuations. More explicity, fathers and their sons are totally unrelated insofar as the genetic complement of their X chromosome is concerned. Under these circumstances, chance events could bring about relatively large integenerational differences in males, as we have previously indicated for crown size (Garn, Lewis and Walenga, '68). Given the present evidence for at least partial involvement of the $\mathrm{X}$ chromosome in tibial length and stature, one might anticipate greater intergenerational differences in stature between fathers and sons than between mothers and their daughters. Furthermore, the effects of hybridization would then be greater for males in the first filial generation than for females in the first filial generation, a suggestion that is easily subject to test. Indeed, for dimensional traits that are largely or exclusively X-linked the effects of hybridization would, initially, be totally different for sons and daughters respectively.

Putting all of our data together, both dental and skeletal, dimensional and developmental, plus English and Canadian data on crown size, pairing siblings and 
parents and their children, the classical assumption of at least partial mediation of the $X$ chromosome appears to hold. This may be a function of the genes involved, thus allowing the possibility of either selective or random inactivation of other genes on the $\mathrm{X}$ chromosome. This may be a total-chromosome effect, of which we have some evidence in our intra-sibship similarities in the magnitude of sexual dimorphism. This could even be populationspecific, allowing for the possibility of either random or selective inactivation of one or the other $\mathrm{X}$ chromosome in populations other than the one described here. The parsimonious explanation, however, is that of (partial) X-mediation of tibial lengths and body length as well as other diameters of bones and teeth and postnatal timing of dental development and of the bony nuclei of round bones, epiphyses of tubular bones and (even) of some primary centers.

\section{ACKNOWLEDGMENTS}

The authors acknowledge the invaluable assistance of Patricia S. Gindhart in setting up and executing the GADRS program for automated roentgenogrametry and the assistance of Guido Wernicke and the Fels computer facility in completing the data analysis. This study was begun under Grant AM 03816 from the National Institutes of Heatlh and completed under Grant AM 13378 to the Center for Human Growth and Development. Shirley M. Garrett assisted in the manuscript preparation.

\section{LITERATURE CITED}

Acheson, R. M. 1966 Maturation of the skeleton. In: Human Development. F. Falkner, ed. W. B. Saunders, Philadelphia. pp. 465-502.
Garn, S. M., G. Greaney and R. Young 1956 Fat thickness and growth progress during infancy. Human Biology, 28: 232-250.

Garn, S. M., R. S. Kerewsky and A. B. Lewis 1966 Extent of sex influence on Carabelli's polymorphism. J. Dent. Res., 45: 1823.

Garn, S. M., A. B. Lewis and R. S. Kerewsky 1965a Genetic, nutritional, and maturational correlates of dental development. J. Dent. Res., 44: $228-242$.

$1965 \mathrm{~b}$ X-linked inheritance of tooth size. J. Dent. Res., 44: 439-441.

1967 Communalities in the size differences of teeth of brothers and sisters. Arch. Oral Biol,, 12: 575-581.

Garn, S. M., A. B. Lewis and A. Walenga 1968 Evidence for a secular trend in tooth size over two generations. J. Dent. Res., 47: 503.

Garn, S. M., and L. D. McCreery 1969 Variability of postnatal ossification timing and evidence for a "dosage" effect. Am. J. Phys. Anthrop., in press.

Garn, S. M., and C. G. Rohmann 1962a X-linked inheritance of developmental timing in man. Nature, 196: 695-696.

1962b Parent-child similarities in handwrist ossification. Am. J. Dis. Child, 103; 603697.

1966 Interaction of nutrition and genetics in the timing of growth and development. Pediat, Clin. N. Amer., 13: 353-379.

Garn, S. M., C. G. Rohmann and A. A. Davis 1963 Genetics of hand-wrist ossification. Am. J. Phys. Anthrop., 21: 33-40.

Garn, S. M., C. G. Rohmann and K. P. Hertzog 1969 Apparent influence of the $X$ chromosome on timing of 73 ossification centers. Am. J. Phys. Anthrop., 30: 123-128.

Garn, S. M., and Z. Shamir 1958 Methods for research in human growth. Charles $C$ Thomas, Springfield.

Garn, S. M. 1966 Body size and its implications. In: Review of Child Development Research. L. W. Hoffman and M. L. Hoffman, eds. Russel Sage Foundation, New York.

Goose, D. A. 1967 Preliminary study of tooth size in families. J. Dent. Res., 46: 959-962.

Hunt, E. E. 1966 The developmental genetics of man. In: Human Development. F. Falkner, ed. W. B. Saunders. Philadelphia. pp. 76-122.

Lewis, D. W., and R. M. Grainger 1967 Sexlinked inheritance of tooth size. A family study. Arch. Oral Biol., 12: 539-544. 